\title{
Analysis of Fatty Acid Composition and Healthy Lipids Indices in Raw and Processed Milk
}

\author{
Lina Laučienè ${ }^{1, *}$, Vaida Andrulevičiūtè², Ingrida Sinkevičienè ${ }^{2}$, Antanas Sederevičius ${ }^{3}$, \\ Kristina Musayeva ${ }^{3}$, Loreta Šrniené ${ }^{1}$ \\ ${ }^{1}$ Department of Food Safety and Quality, Veterinary Faculty, Lithuanian University of Health Sciences, Kaunas, Lithuania \\ ${ }^{2}$ Department of Biochemistry, Veterinary Faculty, Lithuanian University of Health Sciences, Kaunas, Lithuania \\ ${ }^{3}$ Department of Anatomy and Physiology, Veterinary Faculty, Lithuanian University of Health Sciences, Kaunas, Lithuania \\ *Corresponding author: lina.lauciene@lsmuni.lt
}

Received March 10, 2019; Revised April 19, 2019; Accepted May 06, 2019

\begin{abstract}
The aim of the present study was to examine the fatty acid composition and healthy lipids indices in raw milk and dairy products, covering the main stages of production. The fresh cheese, butter, sour cream, and ultra-high temperature treated milk, representing differences in technological approach were chosen for the study. Fatty acids methyl esters were quantified using a gas chromatograph equipped with flame ionization detector and a capillary column SP-2560. No significant influence of the technological process has been identified. The concentrations and profile of fatty acids and healthy lipids indices in final product fat were primarily dependent on the content of the raw milk or cream. The significant difference $(\mathrm{P}<0.05)$ in main groups of fatty acids and healthy lipids indices were determined according to the season (except for sour cream). Summer raw milk and cream was a healthier option for the production of fresh cheese, ultra-high temperature milk, and butter.
\end{abstract}

Keywords: bovine milk, fatty acids, health lipid indices, milk processing

Cite This Article: Lina Laučienė, Vaida Andrulevičiūtè, Ingrida Sinkevičienė, Antanas Sederevičius, Kristina Musayeva, and Loreta Šerniené, "Analysis of Fatty Acid Composition and Healthy Lipids Indices in Raw and Processed Milk.” Journal of Food and Nutrition Research, vol. 7, no. 5 (2019): 386-390. doi: 10.12691/jfnr-7-5-8.

\section{Introduction}

Milk is the most valuable among all plant and animal products. This is due to the unique composition of the milk and its nutritional value, which makes it possible for milk to replace any of the foods. Milk contains all the necessary nutrients for the human body: proteins, fats, lactose, micro and macro elements, vitamins and enzymes ensure normal human growth, development and vital functions of the body [1]. Milk fat is one of the most complex natural fats that consist of approximately 400-500 fatty acids (FA) [2]. The human body absorbs about 97 percent of the milk fat and supplies the essential polyunsaturated fatty acids (PUFA). Two main and essential PUFA are linoleic acid (18:2n6; LA) and $\alpha$ linolenic acid (18:3n3; ALA) which represent the $n 6$ and n3 of PUFA group respectively, are not synthesized in the human body and should be obtained with food [3]. C18:1c9 (oleic acid) which is the most abundant fatty acid of monounsaturated fatty acids (MUFA) and the isomers of conjugated linoleic acid, related to the cholesterol reduction and to the anticarcinogenic effects respectively [4].

Despite benefits, for a long time bovine milk was thought to contribute to cardiovascular disease (CVD) due to negative effects of saturated fatty acids (SFA) which account for $65-75 \%$ of all milk fat. However, recent deacade findings have indicated that the impact of SFA to CVD may be less pronounced than previously assumed. It has been shown that not all SFA are created equal and that the presence of specific fatty acids in circulation are associated with a lower incidence of several cardiometabolic diseases [5]. Now, it is stated the increased low-density lipid (LDL) blood concentration is attributable to C12:0 (lauric), C14:0 (myristic), and C16:0 (palmitic) acids, while other SFA found in milk neutralise their effect since they increase high-density lipids (HDL) level [6] or has no effect on LDL because is poorly absorbed in the gut (eg. C18:0, stearic acid) [7]. Even trans FA from ruminant sources may have cardioprotective effects [1].

The FA profile of dairy fat is important for the nutritional quality of dairy products. To acsses the diet nutrition value and consumer health the ratio of PUFA/SFA and LA/ALA, desirable fatty acids (DFA), hypocholesterolemic/hypercholesterolemic index $(\mathrm{h} / \mathrm{H})$, atherogenicity index (AI) and thrombogenicity index (TI) are valued widly. In 1991, according to the different effect and link to coronary heart disease of the various FA, it was suggested to calculate the AI and TI that can more reliably measure potential of the diet than a ratio of PUFA/SFA [8]. The $\mathrm{h} / \mathrm{H}$ takes into account the known effects of certain FA (C18:1, PUFA, C14:0, C16:0) on cholesterol metabolism [9]. DFA are expressed as the sum 
of unsaturated fatty acids (UFA) plus C18:0 (stearic acid) [10].

A PUFA/SFA ratio above 0.45 is recommended in the diet to prevent coronary heart disease and cancers [11]. According reglamentation from European Union, the levels of LA and ALA should cover a ratio between 5-6. Nevertheless, the optimal ratio should be $2: 1$ to $3: 1$ whereas lower ratio of omega-6/omega-3 FA is more desirable in reducing the risk of many of the chronic diseases [12]. The lower values of AI and TI, that indicate high quantities of anti-atherogenic FA in fat, are recommended for a healthy diet [9].

A number of already known factors such as feeding ration, season, stage of lactation, pregnancy, breed or genotype, parity and stage of lactation, dairy production system factors can greatly influence the profile of FA in milk $[13,14,15,16]$. There were described health lipid indices (HLI) in raw milk depending on the cow breed $[9,17]$, feeding ratio [15], the species of animal $[16,17]$. But there is still lack of information on HLI in different stages of dairy technological process. It is not clear whether all of the FA are transferred from the raw material to the final product, whether and in what way their ratio changes, are there any loss of certain FA and changes in HLI during production, simultaneously. Therefore, the purpose of this study was to analyze the extent of FA transfer from raw milk fat to dairy product and evaluate the nutritional value of dairy fats according to PU FA/SFA, LA/ALA, h/H, DFA, AI and TI during raw milk processing.

\section{Materials and Methods}

\subsection{Samples and Reagents}

Several dairy products such as fresh cheese, butter, sour cream and ultra-high temperature treated (UHT) milk, representing differences in technological approach were chosen for the study. Each product was examined two times. The samples from the main technological stages (Table 1) were collected at one branch of Lithuanian dairy factory during June-July period and January-February period in 2018. The products were manufactured following standard methods [18]. All chemicals and FAME standards for Gas Chromatographic (GC) Analysis were purchased from Merck (KGaA, Darmstadt, Germany).

Table 1. Sampling scheme

\begin{tabular}{ccccc}
\hline Product & \multicolumn{4}{c}{ Sampling points* } \\
\hline Fresh cheese & raw milk & standardized milk & fresh cheese & whey \\
\hline Butter & $\begin{array}{c}\text { bulk butter } \\
\text { cream }\end{array}$ & butter & butter milk & - \\
\hline Sour cream & bulk cream & $\begin{array}{c}\text { standardized and } \\
\text { pasteurized cream }\end{array}$ & sour cream & - \\
\hline UHT milk & raw milk & standardized milk & UHT milk & - \\
\hline
\end{tabular}

*Each sample was taken and analyzed in triplicate.

\subsection{Lipid Extraction}

The lipid separation from liquid samples (milk, cream, buttermilk, whey) was done by centrifugation. The lipids from cheese were extracted using hexane: $10 \mathrm{~g}$ of sample were dispersed with $15 \mathrm{ml}$ hexane using a homogenizer (IKA T25 digital ULTRA TURAX) for $3 \mathrm{~min}$, shaken mechanically and then centrifuged at $5000 \mathrm{rpm}$ for $20 \mathrm{~min}$. The upper solvent was removed and the sediment extracted again twice. The solvents with dissolved fats were combined and evaporated with a rotary evaporator (IKA, RV 10 basic) under vacuum [19].

\subsection{Fatty Acids Analysis}

The FA were converted into fatty acid methyl esters (FAME) as follows [20]: $60 \mathrm{mg}$ of concentrated fat was mixed with $4 \mathrm{ml}$ of hexane and $200 \mu \mathrm{l}$ of $2 \mathrm{molL}^{-1} \mathrm{KOH}$ in methanol, then $1 \mathrm{~min}$ intensively vortexed and after 10 min of standing the top layer was collected and filtered in to chromatography vial. FAME were quantified using a GC Clarus 680 (Perkin Elmer) equipped with flame ionisation detector (FID) and a capillary column SP-2560, $100 \mathrm{~m} \mathrm{x} 0.25 \mathrm{~mm}$ id $\times 0.20 \mu \mathrm{m}$. Conditions for chromatographic analysis were as following: the injector and detector temperatures were maintained at $250{ }^{\circ} \mathrm{C}$. FA profiles were determined by injection of $1 \mu \mathrm{L}$, with a split ratio of $1: 19$. Oven temperature was held at $100^{\circ} \mathrm{C}$ for 4 min, increased to $240^{\circ} \mathrm{C}\left(4^{\circ} \mathrm{C} / \mathrm{min}\right)$ and held for $70 \mathrm{~min}$. Carrier gas (He) flow rate was $20 \mathrm{~mL} / \mathrm{min}$. FA peaks were identified using using Supelco ${ }^{\circledR} 37$ Component FAME Mix. Each FA was expressed in g/100 g of total FAME content.

FA were divided into four main groups depending on the presence and the number of double or triple bonds: saturated fatty acids (SFA), unsaturated fatty acids (UFA), monounsaturated fatty acids (MUFA) and polyunsaturated fatty acids (PUFA).

Indices of atherogenicity (AI) and thrombogenicity (TI) were counted according following formulas [8]:

$$
\mathrm{TI}=\frac{\mathrm{AI}=\frac{(\mathrm{C} 12: 0+(4 \times \mathrm{C} 14: 0)+\mathrm{C} 16: 0)}{(\mathrm{PUFA}+\mathrm{MUFA})}}{\left[\begin{array}{l}
(0.5 \times \mathrm{M} \text { MUFA })+(0.5 \times \mathrm{n} \text { nPUFA }) \\
+(3 \times \text { n3PUFA })+(\text { n3PUFA } / \text { n6PUFA })
\end{array}\right]} .
$$

The hypocholesterolaemic and hypercholesterolaemic $(\mathrm{h} / \mathrm{H})$ index was counted as follows (9):

$$
\mathrm{h} / \mathrm{H}=\frac{(\mathrm{C} 18: 1+\mathrm{PUFA})}{(\mathrm{C} 14: 0+\mathrm{C} 16: 0)} \text {. }
$$

Desirable fatty acids (DFA) were expressed as the sum of unsaturated fatty acids (UFA) and C18:0 (stearic acid) according this formula [10]:

$$
\mathrm{DFA}=\mathrm{UFA}+\mathrm{C} 18: 0 \text {. }
$$

\subsection{Statistical Analysis}

The experiment was designed as a factorial experiment with product and processing treatment as the main factors. Statistical analysis was performed by SPSS statistical package (Chicago, SPSS Inc., SPSS 17). The data were analysed using Descriptive Statistics (Explore) and Analysis of Variance (ANOVA) methods. The 
significance of interactions among the groups assessed was determined by the Tukey HSD test. The differences were considered as significant at $\mathrm{P}<0.05$.

\section{Results and Discussion}

Analysis of summer and winter raw milk samples confirmed other author's findings [21,22]: summer milk had significantly $(\mathrm{p}<0.05)$ more UFA and MUFA and less SFA than winter milk (Figure 1). The PUFA level was similar in milk fat of both seasons.

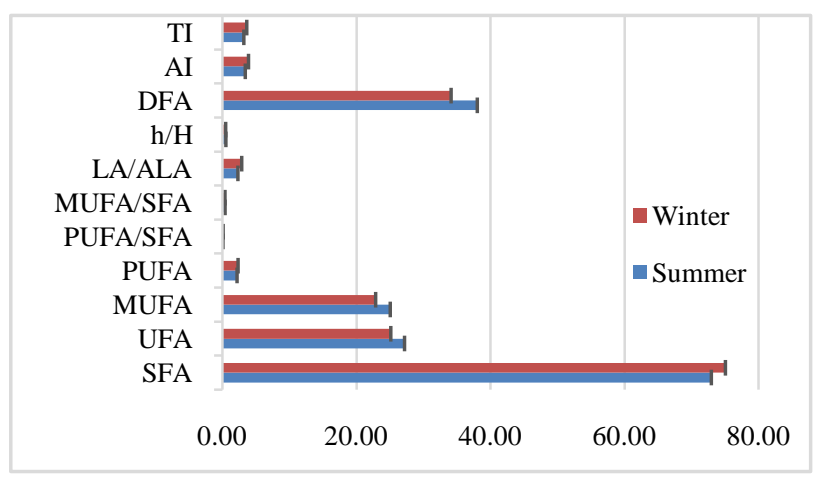

Figure 1. The health lipid indices and percentage composition of main groups of FA in raw milk samples

The PUFA/SFA ratio was much lower $(0.03 \pm 0.00)$ than recommended value $(0.45)$ in both seasons milk. The LA/ALA ratio was $2.25 \pm 0.10$ for raw summer milk and $3.02 \pm 0.13$ for raw winter milk. Although the LA/ALA ratio was significantly lower in summer milk, the milk fat of both seasons was consistent with and even exceeded recommendations.

In addition, summer milk had significantly higher content of DFA and higher $\mathrm{h} / \mathrm{H}$ index as well. Obviously, that AI and TI were lower $(p<0.05)$ in summer milk. Despite very low ratio of PUFA/SFA, summer milk is a healthier option for human nutrition. On the other hand, not all SFA are harmful to human health. The most unwanted and related to cardiovascular disease FA (C12:0, C14:0 and C16:0) [6] were accounted for 53\% of all SFA in raw milk samples in this study.
The seasonal impact, which is most closely associated with cow's feeding ration [13], is evident on milk FA composition and HLI. Since the cow's breed has an influence on FA composition and HLI [9] it is necessary to mention that analyzed raw milk data largely represent the Lithuanian black and white and Lithuanian red cows' breeds. These two cows' breeds make up 56.71\% and $21.40 \%$, of dairy cows in Lithuania, respectively.

Fresh cheese selected for the study was manufactured from standardized, pasteurized and cooled milk by adding mesophilic lactic acid bacteria (LAB, Lactobacillus lactis subsp cremoris, subsp. lactis, subsp. lactis biovar diacetylactis and Leuconostoc subs). After 12 hours of fermentation, curd body was sliced and warmed to $65^{\circ} \mathrm{C}$ to separate the whey. Milk fermentation and whey separation could be identified as the most important stages in production of fresh cheese. However, milk fermentation did not have any impact on main FA groups during both seasons. And the similar amount of FA were transferred from curd body to whey. Hence, the HLI and ratio of PUFA/SFA and LA/ALA remained stable during whole fresh cheese production. The 2005 study did not showed a significant differences in FA profile between raw sheep milk and fresh cheese/ricotta fats. Authors state that concentrations of FA in fresh cheese fat were primarily dependent on the FA content of the raw milk [24]. That is in accordance with our findings with bovine milk. Fresh cheese made during summer period had healthier ratio of FA, more DFA acids and better AI and TI than cheese produced during winter (Table 2).

Unsalted 82 \% fat butter was chosen for our study. Churning was the main stage in the butter-making process that destroyed fat globule's membranes. Very little data available on FA profile changes during butter production, but 2007 study showed that butter-making process had no significant influence on the conjugated linoleic acid and FA content of cream processed into butter [25]. The data of current study presented similar results: the profile and concentrations of FA remained similar during all technological stages. But the difference between analogous samples in a different season was confirmed (Table 3). Since summer butter had less SFA and more UFA and MUFA, the AI and DFA values were rated as healthier.

Table 2. The concentration of main groups and ratios of FA and HLI indices during fresh cheese production in diferent season

\begin{tabular}{|c|c|c|c|c|c|c|c|c|}
\hline & \multicolumn{4}{|c|}{ Summer } & \multicolumn{4}{|c|}{ Winter } \\
\hline & Raw milk & Standardized milk & Fresh cheese & Whey & Raw milk & Standardized milk & Fresh cheese & Whey \\
\hline & $72.88 \pm 0.55^{\mathrm{a}}$ & $72.93 \pm 0.05^{\mathrm{a}}$ & $73.50 \pm 0.56^{\mathrm{a}}$ & $72.33 \pm 0.91^{\mathrm{a}}$ & $76.51 \pm 0.27^{\mathrm{b}}$ & $75.16 \pm 1.19^{b}$ & $76.85 \pm 0.19^{\mathrm{b}}$ & $77.91 \pm 1.30^{\mathrm{b}}$ \\
\hline UFA & $27.12 \pm 0.54^{\mathrm{a}}$ & $27.07 \pm 0.04^{\mathrm{a}}$ & $26.50 \pm 0.53^{\mathrm{a}}$ & $27.67 \pm 0.89^{\mathrm{a}}$ & $23.49 \pm 0.25^{\mathrm{b}}$ & $24.84 \pm 1.17^{\mathrm{b}}$ & $23.15 \pm 0.18^{\mathrm{b}}$ & $22.09 \pm 1.28^{\mathrm{b}}$ \\
\hline MUFA & $25.09 \pm 0.48^{\mathrm{a}}$ & $24.79 \pm 0.13$ & $24.51 \pm 0.49^{a}$ & $25.50 \pm 0.87^{\mathrm{a}}$ & $21.33 \pm 0.11^{b}$ & $22.88 \pm 0.94$ & $21.24 \pm 0.26^{\mathrm{b}}$ & $20.08 \pm 1.26^{\mathrm{b}}$ \\
\hline PUFA & $2.03 \pm 0.07$ & $2.28 \pm 0.12$ & $1.99 \pm 0.00$ & $2.18 \pm 0.08$ & $2.16 \pm 0.17$ & $1.96 \pm 0.25$ & $1.91 \pm 0.08$ & $2.01 \pm 0.18$ \\
\hline PUFA/SFA & $0.03 \pm 0.00$ & $0.03 \pm 0.00$ & $0.03 \pm 0.00$ & $0.03 \pm 0.00$ & $0.03 \pm 0.00$ & $0.03 \pm 0.00$ & $0.02 \pm 0.00$ & $0.03 \pm 0.00$ \\
\hline LA/ALA & $2.00 \pm 0.12$ & $2.03 \pm 0.32$ & $2.01 \pm 0.16$ & $2.14 \pm 0.25$ & $2.88 \pm 0.84$ & $2.57 \pm 0.37$ & $2.86 \pm 0.79$ & $2.81 \pm 0.27$ \\
\hline $\mathrm{h} / \mathrm{H}$ & $0.46 \pm 0.02^{\mathrm{a}}$ & $0.46 \pm 0.00^{\mathrm{a}}$ & $0.49 \pm 0.01^{\mathrm{a}}$ & $0.48 \pm 0.03^{\mathrm{a}}$ & $0.37 \pm 0.01^{\mathrm{b}}$ & $0.40 \pm 0.02^{\mathrm{b}}$ & $0.35 \pm 0.01^{\mathrm{b}}$ & $0.37 \pm 0.01^{b}$ \\
\hline DFA & $37.95 \pm 1.11^{\mathrm{a}}$ & $37.93 \pm 0.20$ & $38.26 \pm 0.29^{\mathrm{a}}$ & $39.18 \pm 0.66^{\mathrm{a}}$ & $32.32 \pm 0.26^{\mathrm{b}}$ & $34.24 \pm 1.10$ & $31.91 \pm 0.47^{\mathrm{b}}$ & $30.45 \pm 1.45^{\mathrm{b}}$ \\
\hline $\mathrm{AI}$ & $3.35 \pm 0.11^{\mathrm{a}}$ & $3.37 \pm 0.04$ & $3.46 \pm 0.05^{\mathrm{a}}$ & $3.20 \pm 0.19^{\mathrm{a}}$ & $4.14 \pm 0.11^{\mathrm{b}}$ & $3.78 \pm 0.31$ & $4.23 \pm 0.06^{\mathrm{b}}$ & $4.44 \pm 0.25^{\mathrm{b}}$ \\
\hline $\mathrm{TI}$ & $3.12 \pm 0.09^{\mathrm{a}}$ & $3.07 \pm 0.13$ & $3.11 \pm 0.13^{\mathrm{a}}$ & $3.10 \pm 0.16$ & $3.75 \pm 0.18^{\mathrm{b}}$ & $3.69 \pm 0.19$ & $3.93 \pm 0.08^{\mathrm{b}}$ & $4.39 \pm 0.55$ \\
\hline
\end{tabular}

Values are mean value \pm SEM g/100 g of FAME; means with diferent lowercase letters within the same row show significant (P<0.05) difference between analogous sampes in diferent seasons; SFA-saturated fatty acids, UFA-unsaturated fatty acids; MUFA-monounsaturated fatty acids; PUFApolyunsaturated fatty acids; PUFA/SFA-ratio of polyunsaturated fatty acids and saturated fatty acids; MUFA/SFA-ratio of monounsaturated fatty acids and saturated fatty acids; LA/ALA-ratio of 18:2n6 (linoleic acid) and 18:3n3 ( $\alpha$-linolenic acid); h/H- hypocholesterolaemic and hypercholesterolaemic index; DFA-desirable fatty acids; AI-atherogenicity index; TI-thrombogenicity index. 
Table 3. The concentration of main groups and ratios of FA and HLI indices during butter production in diferent season

\begin{tabular}{|c|c|c|c|c|c|c|}
\hline & Summer & & & Winter & & \\
\hline & Bulk butter cream & Butter & Butter milk & Bulk butter cream & Butter & Butter milk \\
\hline & $70.49 \pm 0.70^{\mathrm{a}}$ & $70.63 \pm 0.75^{\mathrm{a}}$ & $71.21 \pm 0.89^{\mathrm{a}}$ & $75.27 \pm 1.39^{b}$ & $74.12 \pm 0.42^{b}$ & $73.42 \pm 0.50^{b}$ \\
\hline UFA & $29.51 \pm 0.69^{\mathrm{a}}$ & $29.37 \pm 0.72^{\mathrm{a}}$ & $28.79 \pm 0.84^{\mathrm{a}}$ & $24.73 \pm 1.36^{\mathrm{b}}$ & $25.88 \pm 0.40^{\mathrm{b}}$ & $26.58 \pm 0.49^{b}$ \\
\hline MUFA & $27.35 \pm 0.56^{\mathrm{a}}$ & $27.11 \pm 0.68^{\mathrm{a}}$ & $26.51 \pm 1.03^{\mathrm{a}}$ & $22.21 \pm 1.48^{\mathrm{b}}$ & $23.45 \pm 0.43^{b}$ & $23.71 \pm 0.29^{b}$ \\
\hline PUFA & $2.16 \pm 0.14$ & $2.26 \pm 0.07$ & $2.27 \pm 0.14$ & $2.52 \pm 0.09$ & $2.43 \pm 0.00$ & $2.87 \pm 0.21$ \\
\hline PUFA/SFA & $0.03 \pm 0.00$ & $0.03 \pm 0.00$ & $0.03 \pm 0.00$ & $0.03 \pm 0.00$ & $0.03 \pm 0.00$ & $0.04 \pm 0.00$ \\
\hline MUFA/SFA & $0.39 \pm 0.01^{\mathrm{a}}$ & $0.38 \pm 0.01^{\mathrm{a}}$ & $0.37 \pm 0.02^{\mathrm{a}}$ & $0.30 \pm 0.04^{\mathrm{b}}$ & $0.32 \pm 0.01^{\mathrm{b}}$ & $0.32 \pm 0.01^{b}$ \\
\hline LA/ALA & $2.60 \pm 0.02$ & $2.56 \pm 0.18$ & $2.72 \pm 0.34$ & $2.69 \pm 0.05$ & $2.52 \pm 0.26$ & $2.33 \pm 0.08$ \\
\hline $\mathrm{h} / \mathrm{H}$ & $0.56 \pm 0.01$ & $0.53 \pm 0.03$ & $0.49 \pm 0.01$ & $0.41 \pm 0.06$ & $0.43 \pm 0.01$ & $0.47 \pm 0.01$ \\
\hline DFA & $40.60 \pm 0.32^{\mathrm{a}}$ & $41.33 \pm 0.37^{\mathrm{a}}$ & $39.25 \pm 0.38^{\mathrm{a}}$ & $35.21 \pm 0.68^{\mathrm{b}}$ & $35.38 \pm 0.70^{b}$ & $36.17 \pm .0 .71^{b}$ \\
\hline AI & $2.90 \pm 0.06^{\mathrm{a}}$ & $2.91 \pm 0.18^{\mathrm{a}}$ & $3.16 \pm 0.08^{\mathrm{a}}$ & $3.93 \pm 0.53^{b}$ & $3.64 \pm 0.09^{b}$ & $3.33 \pm 0.07^{b}$ \\
\hline TI & $2.77 \pm 0.01$ & $3.04 \pm 0.08$ & $3.00 \pm 0.02$ & $3.45 \pm 0.37$ & $3.31 \pm 0.10$ & $2.97 \pm 0.09$ \\
\hline
\end{tabular}

Values are mean value \pm SEM g/100 g of FAME; means with diferent lowercase letters within the same row show significant $(\mathrm{P}<0.05)$ difference between analogous sampes in diferent seasons; SFA-saturated fatty acids, UFA-unsaturated fatty acids; MUFA-monounsaturated fatty acids; PUFApolyunsaturated fatty acids; PUFA/SFA-ratio of polyunsaturated fatty acids and saturated fatty acids; MUFA/SFA-ratio of monounsaturated fatty acids and saturated fatty acids; LA/ALA-ratio of 18:2n6 (linoleic acid) and 18:3n3 ( $\alpha$-linolenic acid); h/H- hypocholesterolaemic and hypercholesterolaemic index; DFA-desirable fatty acids; AI-atherogenicity index; TI-thrombogenicity index.

Sour cream chosen for this study was manufactured by fermentation of standardized, homogenized and pasteurized cream using LAB strains. During both seasons, FA profile did not change during sour cream processing. Partially this comes in agreement with other findings - no pasteurization effect on milk fat profile [25,26], no homogenization effect on cream [28] or milk [29] FA profiles were found. Meantime, results from previous surveys with milk and cream fermentation were very controversial [29,30,31] pointing out the importance of $\mathrm{LAB}$ strains used for fermentation, with probiotic strains contributing to significant changes in FA distribution. However, the cream fermentation with LAB in our study did not reveal any significant changes in FA profile, therefore HLI and ratio of PUFA/SFA and LA/ALA remained stable during sour cream production. In contrast to other products analysed in this study, significant seasonal effect between summer and winter sour cream was not found either.

The milk treatment with ultra high temperature $\left(135^{\circ} \mathrm{C}\right.$ for $3 \mathrm{sec}$ ) showed a slight change in the amount of individual FA during UHT milk processing. For instance, the amounts of short chain FA (except C4:0) and midle chain FA tended to decrease, while long chain FA (except C16:0, C17:0) slightly increased after high temperature treatment. However, the significance of these changes in FA profile has not been statistically confirmed. The SFA, UFA, MUFA and PUFA groups remained stable during UHT milk prossesing, therefore, the HLI and FA ratios were not affected. Some authors refer to the significant impact on short chain FA in UHT milk [26,32], but the different heat treatment applied in their study $\left(140^{\circ} \mathrm{C}\right.$ for 3 sec) could have had a significant influence on this change.

\section{Conclusion}

The data analysis showed that technologies such as milk pasteurisation, homogenization, ultra-high temperature treatment, milk or cream fermentation by LAB, cream churning process had no significant effect on the FA profile or the corresponding FA ratio and HLI. In the by-products (whey and butter milk), the FA ratio remained similar. The FA composition and HLI in the final milk products were directly dependent on composition of the raw material.

\section{Conflict of Interest}

The authors declare no conflict of interest.

\section{References}

[1] Lordan, R., Tsoupras, A., Mitra, B. and Zabetakis, I., "Dairy fats and cardiovascular disease: do we really need to be concerned?”, Foods 7(3). 2018.

[2] Jensen, R.G., "The composition of bovine milk lipids", Journal of Dairy Science, 85(2). 295-350. 2002

[3] Ristic-Medic, D., Vucic, V., Takic, M., Karadzic, I. and Glibetic, M., "Polyunsaturated fatty acids in health and disease", Journal of the Serbian Chemical Society, 78 (9). 1269-89. 2013

[4] Haug, A., Høstmark, A.T. and Harstad, O.M., "Bovine milk in human nutrition - a review”, Lipids in Health and Disease, 6 (25). 2007.

[5] Givens, D.I., "Dairy products: good or bad for cardiometabolic disease?”, The American Journal of Clinical Nutrition, 101 (4). 695-696. 2015

[6] Parodi, P.W., "Has the association between saturated fatty acids, serum cholesterol and coronary heart disease been over emphasized?”, International Dairy Journal, 19 (6-7). 345-61. 2009.

[7] Gibson, R.A., "Milk fat and health consequences", Nestlé Nutrition Institute Workshop Series: Pediatric Program, 67. 197-207. 2011.

[8] Ulbricht, T.L. and Southgate, D.A., "Coronary heart disease: seven dietary factors”, Lancet, 338 (8773). 985-92. 1991

[9] Pilarczyk, R., Wójcik, J., Sablik, P. and Czerniak, P., "Fatty acid profile and health lipid indices in the raw milk of Simmental and Holstein-Friesian cows from an organic farm”, South African Journal of Animal Science, 45 (1). 30-38. 2015.

[10] Medeiros, E., Queiroga, R., Oliveira, M., Medeiros, A., Sabedot, M., Bomfim, M. and Madruga, M., "Fatty Acid Profile of Cheese from Dairy Goats Fed a Diet Enriched with Castor, Sesame and Faveleira Vegetable Oils”, Molecules, 19. 992-1003. 2014.

[11] Simopoulos, A.P., "An increase in the omega-6/omega-3 fatty acid ratio increases the risk for obesity", Nutrients, 8 (3). 2016.

[12] EFSA, 2014., "Scientific Opinion on the essential composition of infant and follow-on formulae", EFSA Journal, 12 (7). 3760. $2014 \mathrm{~m}$.

[13] Morales, R., Lanuza, F., Subiabre, I., Carvajal, A., Canto, F. and Ungerfeld, E., "A comparison of milk fatty acid profile among three different dairy production systems in Los Ríos District, Chile”, Archivos de medicina veterinaria, 47(3). 81-92. 2015. 
[14] Samková, E., Spicka, J., Pesek, M., Pelikánová, T. and Hanus, O., "Animal factors affecting fatty acid composition of cow milk fat: a review”, South African Journal of Animal Science, 42 (2). 83-100. 2012.

[15] Křžžová, L., Ryšavý, J., Richter, M., Veselý, A., Hanuš, O., Janštová, B., Vorlova, V. and Samkova, E., "Milk yield, milk composition, fatty acid profile and indices of milk fat quality as affected by feeding with extruded full-fat soybean”, Mljekarstvo, 67 (1). 49-57. 2017.

[16] Mierlita, D., "Fatty acid profile and health lipid indices in the raw milk of ewes grazing part-time and hemp seed supplementation of lactating ewes”, South African Journal of Animal Science, 46 (3). 237-46. 2016.

[17] Idamokoro, E.M., Muchenje, V., Afolayan, A.J. and Hugo, A., "Comparative fatty-acid profile and atherogenicity index of milk from free grazing Nguni, Boer and non-descript goats in South Africa”, Pastoralism, 9 (1). 4. 2019.

[18] Walstra, P., Dairy Technology: Principles of Milk Properties and Processes, CRC Press; 1999, 752.

[19] GOST 32915-2014. GOST 32915-2014. (2014). Milk and milk products. Determination of fatty acid content by gas chromatography method. Euro-Asian Council for Standardization, Metrology and Certification (EASC).

[20] GOST 31665-2012. GOST 31665-2012. (2012). Vegetable oils and animal fats. Preparation of methyl esters of fatty acids. Euro-Asian Council for Standardization, Metrology and Certification (EASC).

[21] Markiewicz-Kęszycka, M., Czyżak-Runowska, G., Lipińska, P. and Wójtowski, J., "Fatty Acid Profile of Milk - A Review", Bulletin of the Veterinary Institute in Pulawy, 57 (2). 135-9. 2013.

[22] Blasko, J., Kubinec, R., Gorova, R., Fábry, I., Lorenz, W. and Soják, L., "Fatty acid composition of summer and winter cows' milk and butter”, Journal of food and nutrition research, 49 169-77. 2010.

[23] Nudda, A., McGuire, M.A., Battacone, G. and Pulina, G. "Seasonal Variation in Conjugated Linoleic Acid and Vaccenic
Acid in Milk Fat of Sheep and its Transfer to Cheese and Ricotta”, Journal of Dairy Science, 88 (4). 1311-9. 2005.

[24] Bisig, W., Eberhard, P., Collomb, M. and Rehberger, B., "Influence of processing on the fatty acid composition and the content of conjugated linoleic acid in organic and conventional dairy products - a review”. Le Lait, 87 (1). 1-19. 2007.

[25] Pestana, J.M., Gennari, A., Monteiro, B., Lehn, D. and Souza, C., "Effects of Pasteurization and Ultra-High Temperature Processes on Proximate Composition and Fatty Acid Profile in Bovine Milk”, American Journal of Food Technology, 10. 265-72. 2015.

[26] Santos, O.O.J., "Fatty Acid Content of Bovine Milkfat From Raw Milk to Yoghurt”, American Journal of Applied Sciences, 9(8) 1300-6. 2012

[27] Pirisi, A., Salvatore, E., Cabiddu, A., Pes, M., Furesi, S., Decandia, M., Molle, G., Piredda, G. and Addis, M., "Effect of Milk Cream Homogenization on the Beneficial Fatty Acids in PDO Pecorino Sardo and Ricotta Cheese", 5th International Symposium: The Challenge to Sheep and Goats Milk Sectors, 2007.

[28] Michalski, M.C. and Januel, C., "Does homogenization affect the human health properties of cow's milk?”, Trends in Food Science \& Technology, 17 (8). 423-37. 2006.

[29] Yilmaz-Ersan, L., "Fatty acid composition of cream fermented by probiotic bacteri”, Mljekarstvo, 63 (3). 132-139. 2013.

[30] Yadav, H., Jain, S. and Sinha, P.R., "Production of free fatty acids and conjugated linoleic acid in probiotic dahi containing Lactobacillus acidophilus and Lactobacillus casei during fermentation and storage”, International Dairy Journal, 17(8). 1006-1010. 2007.

[31] Serafeimidou, A., Zlatanos, S., Kritikos, G. and Tourianis, A. "Change of fatty acid profile, including conjugated linoleic acid (CLA) content, during refrigerated storage of yogurt made of cow and sheep milk", Journal of Food Composition and Analysis, 31(1). 24-30. 2013.

[32] Ajmal, M., Nadeem, M., Imran, M. and Junaid, M., "Lipid compositional changes and oxidation status of ultra-high temperature treated Milk", Lipids in Health and Disease, 17(1). 227. 2018. 